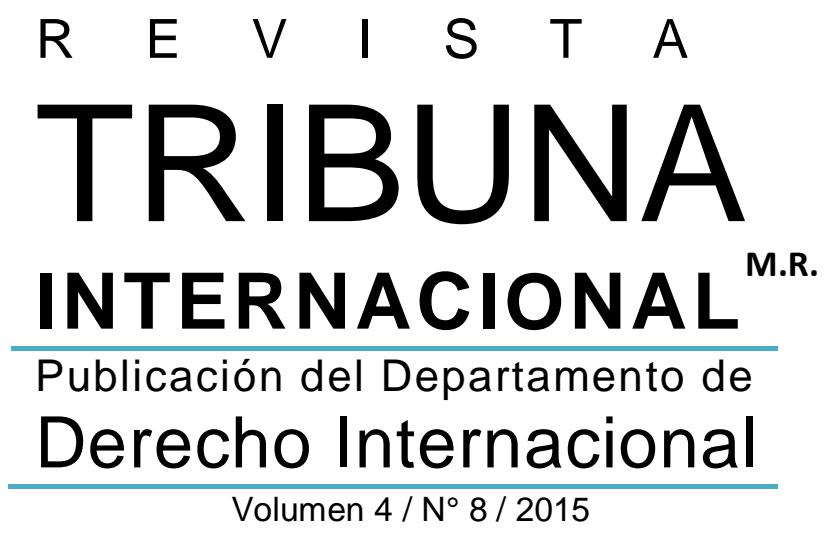

FACULTAD DE

DERECHO

UNIVERSIDAD DE CHILE 


\section{Rector de la Universidad de Chile}

Ennio Vivaldi Véjar

Av. Alameda Libertador Bernardo O'Higgins

1058, Santiago

\section{Representante legal}

Davor Harasic Yaksic

Decano de la Facultad de Derecho

Universidad de Chile

\section{Director Departamento Derecho}

Internacional

Edmundo Vargas Carreño

\section{Director (S) Revista Tribuna Internacional}

Mario Arnello Romo

\section{Editor General Revista Tribuna Internacional}

Luis Valentín Ferrada Walker

\section{Comité Editorial}

Íñigo Álvarez Gálvez (Universidad de Chile, Chile)

Gonzalo Aguilar (Universidad de Talca, Cbile)

José Carlos Fernández Rosas (Universidad

Complutense de Madrid, España)

Claudio Grossman (American University, EE.UU.)

Mattias Kumm (New York University, EE.UU.)

Hugo Llanos (Universidad Central, Chile)

Cecilia Medina (Universidad Diego Portales, Chile)

Elina Mereminskaya (Universidad de Chile, Chile)

Mónica Pinto (Universidad de Buenos Aires, Argentina)

\section{Fundador de la Revista Tribuna Internacional}

Mario Ramírez Necochea †

\section{Revista Tribuna Internacional M.R.}

Publicación del Departamento de Derecho Internacional de la Facultad de Derecho de la Universidad de Chile. Su objetivo es fomentar la reflexión, el debate, el análisis y la comunicación sobre el derecho internacional en forma pluralista y con rigor científico. Se publica cada semestre en los meses de junio y diciembre mediante convocatoria abierta a la publicación de artículos y monografías inéditos, comentarios de jurisprudencia, recensiones y comentarios de libros, en los campos de derecho internacional público y privado, derecho internacional de los derechos humanos y relaciones internacionales, tanto en castellano como inglés.

La Revista Tribuna Internacional fue creada por Decreto Exento No 8.466 de la Rectoría de la Universidad de Chile, de 22 de marzo del 2011.

Volumen 4/ No 8 / 2015

www.tribunainternacional.uchile.cl ISSN 0719-482X (versión en línea)

Departamento de Derecho Internacional Facultad de Derecho Universidad de Chile Av. Santa María 076, $4^{\circ}$ piso

Providencia, Santiago de Chile

\section{Diseño y producción:}

Facultad de Derecho

Universidad de Chile

Se autoriza la reproducción total o parcial del contenido de la publicación, siempre que se reconozca y cite el/ la/ los/ las autor/a/es/as y la publicación, no se realicen modificaciones a la obra y no se la utilice para fines comerciales. 


\title{
Recepción en Chile de la Ley Modelo sobre Insolvencia Transfronteriza de la Comisión de las Naciones Unidas para el Derecho Mercantil Internacional: Breve análisis del centro de principales intereses del deudor como nuevo factor de conexión ${ }^{1}$
}

\author{
Reception in Chile of the United Nations Commission on International Trade Law Model \\ Law on Cross-Border Insolvency: Brief analysis of the center of main interests of the debtor \\ as a new connecting factor
}

\author{
Jeremy Daniel Levy Morchio \\ jeremylevym@gmail.com \\ Egresado de Derecho, Universidad de Chile.
}

\begin{abstract}
Resumen: Este artículo analiza la Ley Modelo sobre insolvencia transfronteriza de la Comisión de las Naciones Unidas para el Derecho Mercantil Internacional (CNUDMI) y su incorporación al derecho nacional por medio de la entrada en vigencia de la nueva Ley de Insolvencia y Reemprendimiento, poniendo especial atención en el concepto de centro de principales intereses del deudor, como nuevo factor de conexión entre jurisdicciones. Para esto se hará un recorrido comenzando por la situación de la insolvencia transfronteriza en Chile previo a la nueva ley, se analizara el origen, estructura y objetivos de Ley Modelo y la forma en que se introdujo en Chile, para finalmente estudiar el concepto de centro de principales intereses del deudor.
\end{abstract}

Palabras Clave: Insolvencia transfronteriza - nueva Ley de Insolvencia y Reemprendimiento Ley Modelo de insolvencia transfronteriza

\begin{abstract}
This article analyze the United Nations Commission on International Trade Law (UNCITRAL) Model Law on Cross-border Insolvency and its incorporation into national law by means of the entry into force of the new Law of Insolvency and Re-entrepreneurship, paying special attention to the concept of center of main interests of the debtor, as a new factor of connection between jurisdictions. For this, we will begin with the situation of cross-border insolvency in Chile prior to the new law, will analyze the origin, structure and objectives of the model law and the way in which was introduced in Chile, to finally study the concept of center of main interests of the debtor.
\end{abstract}

Keywords: Cross-border Insolvency - New Law on Insolvency and Re-entrepreneurship - Model Law on Cross-border Insolvency

1 Artículo recibido el 04.10.2015 y aceptado el 10.12.2015. 


\section{Introducción}

Al entrar en vigencia la nueva Ley de Insolvencia y Reemprendimiento, Ley $\mathrm{N}^{\circ}$ 20.720-2014 (en adelante NLI), que sigue en línea generales la Ley Modelo propuesta por la Comisión de las Naciones Unidas para el Derecho Mercantil Internacional (en adelante CNUDMI), ingresó junto con ella un nuevo factor de conexión en el Derecho nacional, cual es el centro de principales intereses del deudor. Este nuevo factor de conexión, tendrá una relevancia gravitante en la determinación de cuál, entre todos los procedimientos de insolvencia que se han abierto en el extranjero en contra de un deudor, será el que tendrá la calidad de procedimiento extranjero principal, vinculando la jurisdicción chilena con alguna de las posibles jurisdicciones extranjeras que hayan conocido de su insolvencia.

El centro de principales intereses del deudor en cuanto factor de conexión entre dos jurisdicciones, requiere una investigación como la que se presenta en este trabajo, por la novedad que tiene en el sistema jurídico chileno y por sobre todo, por ser un concepto jurídico indeterminado que ha generado vasta doctrina y jurisprudencia internacional, que ha intentado delimitar su contenido.

\section{La insolvencia transfronteriza}

\subsection{Una posible definición}

La insolvencia transfronteriza puede definirse como aquella en la que existe más de un país involucrado en la insolvencia de la empresa o persona. El profesor Contreras Strauch le da el carácter de fronteriza a una insolvencia cuando en ella el deudor insolvente tiene bienes, agencias, sucursales o establecimientos en más de un Estado, o bien, cuando algunos de los acreedores del deudor no son ciudadanos del país en donde se ha abierto el procedimiento concursal ${ }^{2}$.

De la definición citada, son dos los elementos internacionales que pueden hacer a una insolvencia adquirir un aspecto internacional: la presencia de bienes y empresas relacionadas o la existencia de acreedores en un país distinto al cual se abrió el procedimiento de insolvencia. Así también lo caracterizan los profesores Eyzaguirre y Gómez: La insolvencia transnacional involucra un procedimiento de insolvencia en un determinado país con acreedores localizados

2 COntreras, Osvaldo. Insolvencia y quiebras. Santiago, Editorial Jurídica de Chile, 2010, p. 451. 
Revista Tribuna Internacional

Volumen $4 \cdot \mathrm{N}^{\circ} 8 \cdot 2015 \cdot$ pp. 165-183

ISSN 0719-482X (versión en línea)

en a lo menos un país adicional. En los casos más complejos involucra múltiples procedimientos, subsidiarias, entidades afiliadas, activos, operaciones y acreedores localizados en distintos países ${ }^{3}$.

Sin perjuicio de estas definiciones, más adelante veremos que la Ley Modelo sobre insolvencia transfronteriza propuesta por la CNUDMI y en la que se basa en líneas generales la nueva ley chilena sobre la materia, considera principalmente la existencia de un procedimiento extranjero como elemento determinante para hacer aplicables sus normas.

\subsection{Estado de la materia previo a la nueva ley}

\subsubsection{El Código de Bustamante y el antiguo Libro IV del Código de Comercio}

Hasta antes de la entrada en vigencia de la NLI, las referencias en nuestro sistema jurídico a la arista internacional de una insolvencia eran escasas y aisladas, sin dar un tratamiento sistemático a la materia. La antigua Ley de Quiebras, solo se refería a los acreedores extranjeros para citarlos a comparecer con los documentos justificativos de sus créditos ${ }^{4}$.

Por su parte, el Convenio que estableció el Código de Derecho Internacional Privado o Código Bustamante (1928), incluía una referencia a la quiebra o concurso en el Título Noveno del Libro Tercero, entre los artículos 414 y 422. Cabe notar que las disposiciones del Código Bustamante fueron aprobadas por Chile bajo reserva de prevalecer la legislación chilena actual o futura por sobre tales normas. Sin perjuicio de lo anterior, el artículo 302 de la NLI establece que en caso de conflicto entre este capítulo y una obligación del Estado de Chile nacida de un tratado u otra forma de acuerdo en el que Chile sea parte con uno o más Estados donde se estén tramitando procedimientos extranjeros, prevalecerán las disposiciones de ese tratado o acuerdo. Tenemos entonces que la reserva del Código Bustamante hacer prevalecer la legislación nacional, pero esta legislación le vuelve a otorgar vigencia a los tratados internacionales. Se produce una colisión entre dos normas que se entregan una a la otra vigencia mutuamente. Debemos concluir que por un criterio de especialidad y posterioridad de la ley, debiera regir la NLI por sobre el Código Bustamante en un caso en que ambos cuerpos legales pudieran arrogarse aplicación.

\subsubsection{Exequátur}

Corresponde, al hacer mención de la legislación referida a la insolvencia extranjera antes de la NLI, detenerse en el exequátur, que si bien no es una materia específicamente relacionada con la

\footnotetext{
EyZaguirre, Gonzalo y Gómez, Rafael. El derecho de quiebras. 2a edición. Santiago, Editorial Jurídica de Chile, 2011, p. 561 Artículo $52 \mathrm{~N}^{\circ} 7$ de la Antigua Ley de Quiebras (Ley N 18.175-1982)

Para un análisis más detallado de las disposiciones del Código de Bustamante, vid. FORTES, Carla. Insolvencia transfronteriza. Memoria para optar al grado de Licenciado en Ciencias Jurídicas y Sociales. Santiago, Universidad de Chile, Facultad de Derecho, 2008, pp. 41 y ss.
} 
insolvencia internacional, si se hace necesaria una breve referencia a fin de constatar los efectos que la NLI produce en esta forma de cooperación internacional.

Como veremos más adelante, la NLI se organiza en base al reconocimiento de un procedimiento de insolvencia extranjero y es el propósito esencial de crear un régimen jurídico aplicable a la quiebra transfronteriza, el facilitar el reconocimiento de los procedimientos extranjeros de insolvencia ${ }^{6}$. Por ende, a primera vista, podría parecer razonable concluir que se vería disminuido el ámbito de aplicación del exequátur, dejando fuera del mismo todos los asuntos concursales.

Sin embargo, esa conclusión podría ser apresurada en base a las diferencias que surgen del estudio de ambos estatutos. La primera diferencia que aparece de manifiesto es que en el caso del exequátur, este busca el reconocimiento de sentencias extranjeras ejecutoriadas en conformidad a las leyes del país en que hayan sido pronunciadas y la Ley Modelo busca el reconocimiento de procedimientos. Reconocer un procedimiento genera un dinamismo mayor, al estar sujeto a los cambios que se produzcan en el procedimiento extranjero ${ }^{7}$. También se desprende una diferencia en el ámbito temporal de aplicación de cada procedimiento, ya que el exequátur se pedirá tras haber concluido el procedimiento en el país extranjero, a diferencia del reconocimiento de procedimientos extranjeros de la NLI, ya que la propia definición de "procedimiento extranjero" se refiere a éste como un procedimiento, que se tramite en un Estado extranjero ${ }^{8}$, por lo que su reconocimiento, se realiza esencialmente durante la tramitación de éste y no necesariamente a su conclusión.

Se puede argumentar que el nuevo procedimiento de reconocimiento, aumenta y facilita el reconocimiento de situaciones jurídicas que podrían quedar fuera del ámbito de aplicación del exequátur, ya que el reconocimiento de un procedimiento de insolvencia extranjera podría no considerarse reconocimiento de una "sentencia" extranjera, por ejemplo, si la declaración extranjera de quiebra se considera meramente una declaración de la situación legal del deudor o no se considera un pronunciamiento de carácter definitivo 9 . De todas formas, creemos que la afirmación que hicimos sobre la reducción del ámbito de aplicación del exequátur con la nueva ley, sigue en pie.

A nivel práctico, creemos que el nuevo procedimiento de reconocimiento reemplazará al exequátur en materias concursales, ya que los actores de una quiebra tienen buenas razones para preferirlo, principalmente en base a que el procedimiento de reconocimiento evita la doble tramitación que imponía el exequátur. Se llega a esta conclusión de la lectura de los artículos

6 SAndoval, Ricardo. "La ley modelo de la CNUDMI sobre quiebra transfronteriza", en Revista de Derecho (Universidad de Concepción), $\mathrm{N}^{\circ} 205,1999$, p. 39.

7 Ejemplo de ello es el artículo 317 de la NLI. Este artículo impone el deber de información continua de todo cambio que ocurra en el procedimiento extranjero.

8 Artículo 301 a) de la NLI.

9 CNUDMI. Ley Modelo de la CNUDMI sobre la Insolvencia Transfronteriza y Guía para su incorporación al derecho interno e interpretación. Viena, 2014. p. 24. [en línea] <http://www.uncitral.org/pdf/spanish/texts/insolven/1997-Model-Law-Insol2013-Guide-Enactment-s.pdf> [consulta: 20 de diciembre del 2015]. 
Revista Tribuna Internacional

Volumen $4 \cdot \mathrm{N}^{\circ} 8 \cdot 2015 \cdot$ pp. 165-183

ISSN 0719-482X (versión en línea)

314, 318, 319 y 320 de la NLI, que aluden a un mismo "tribunal competente" al que deberá solicitar el representante extranjero el reconocimiento de procedimiento extranjero (artículo 314) y que deberá otorgar las medidas a favor del representante extranjero (artículos 318, 319 y 320). Por su parte, la definición de tribunal competente está en la letra h del artículo 301 de la NLI, estableciendo que será aquel tribunal que le hubiere correspondido o que le correspondiera conocer de un procedimiento concursal con arreglo a esta ley. Finalmente el artículo $3^{\circ}$ de la NLI dispone que los procedimientos concursales contemplados en esta ley serán de competencia del juzgado de letras que corresponda al domicilio del deudor. En consecuencia, tanto el reconocimiento de procedimientos extranjeros como las medidas que se otorguen a este, se tramitaran ante los juzgados de letras competentes. Esto en contraste con el exequátur, el que solo una vez tramitado, y habiéndose mandado a cumplir una resolución pronunciada en país extranjero, se puede iniciar otro procedimiento, de tipo compulsivo ante el tribunal al que habría correspondido conocer el negocio si el juicio se hubiera promovido en Chile para su ejecución ${ }^{10}$. De todas formas, creemos que ambos procedimientos son complementarios y que ambos siguen estando vigentes para ser solicitados en materias concursales, sin derogación tácita del exequátur. Quedará en manos de los acreedores extranjeros definir qué procedimiento les acomoda más para el logro de sus intereses.

\subsection{Origen y objetivos de la Ley Modelo}

Habiendo estudiado el estado de la materia previo a la nueva ley pasamos a revisar el origen directo de las normas internacionales contempladas en la NLI.

Durante su $30^{\circ}$ periodo de sesiones celebrado en Viena del 12 al 30 de mayo de 1997, la CNUDMI aprobó la Ley Modelo sobre insolvencia transfronteriza ${ }^{11}$.Su principal objetivo, tal como lo reseña la guía para su incorporación al derecho interno, es ayudar a los Estados a dotar a su régimen de insolvencia de una normativa moderna, equitativa y armonizada para abordar con más eficacia los casos de procedimientos transfronterizos ${ }^{12}$.

El aumento del comercio internacional ha hecho que desde la década de 1990 la cantidad de insolvencias que tienen repercusiones internacionales haya aumentado significativamente. Este aumento de casos de insolvencia trasfronteriza ha ido de la mano con el aumento de operaciones fraudulentas de los deudores para ocultar bienes en el extranjero, lejos del alcance de los acreedores, operaciones de cada vez de mayor facilidad por la globalización de las economías. Por otra parte, la mayoría de las naciones no ha previsto para sus legislaciones nacionales normas que gobiernen situaciones como estas, lo que redunda por un lado en una falta de previsibilidad en lo que sucederá con los bienes o dineros que el deudor tiene en países

Artículo 251 del Código de Procedimiento Civil.

11 Para mayor información sobre los antecedentes de la Ley Modelo, vid. SANDOval, "La ley modelo de la CNUDMI...", op.cit., pp. 33-35.

12 CNUDMI. Ley Modelo de la CNUDMI... y Guía para su incorporación, op.cit., p. 21. 
extranjero, así como también en el uso de mecanismos de cooperación que no fueron creados para esos fines, siendo de difícil tramitación y de incierto resultado, como el exequátur y la doctrina de la cortesía internacional en el common law.

Todas estas razones llevo a la CNUDMI a iniciar en 1995 un proceso de elaboración de un texto legal que sirviera para dar solución a la insolvencia transfronteriza, que incluyo la participación de diversos organismos internacionales y que culmino en 1997 con la aprobación de la actual Ley Modelo ${ }^{13}$.

\subsection{Estructura de la Ley Modelo}

El texto de la Ley Modelo se centra en cuatro elementos fundamentales que, tras los estudios y consultas realizados a principios de los años de 1990, antes de su negociación, se reconocieron como ámbitos en los que tal vez se podría alcanzar un acuerdo internacional:

a) El acceso a los tribunales de un Estado para los representantes de procedimientos de insolvencia sustanciados en el extranjero y para los acreedores, y la autorización a los representantes de procedimientos de un Estado para solicitar asistencia en otro;

b) El reconocimiento de determinadas órdenes dictadas por tribunales extranjeros;

c) El otorgamiento de medidas para ayudar a sustanciar procedimientos extranjeros;

d) La cooperación entre los tribunales de los Estados en que estén situados los bienes del deudor y la coordinación de procedimientos paralelos ${ }^{14}$.

Los 32 artículos de Ley Modelo están divididos en el preámbulo y cinco capítulos. Aparte del Capítulo I que trata sobre disposiciones generales, el resto de los capítulos se estructuran recogiendo los ejes fundamentales recién mencionados. De esta manera el Capítulo II se refiere al acceso de los representantes y acreedores extranjeros a los tribunales del Estado; el Capítulo III -que es el que más interesa a esta investigación junto con el capítulo I de las disposiciones generales- regula el reconocimiento de un procedimiento extranjero y las medidas otorgables; el Capítulo IV trata sobre la cooperación con tribunales y representantes extranjeros; y finalmente, el Capítulo V, trata sobre los procedimientos paralelos.

13 A la fecha, la Ley Modelo ha sido adoptada, o se han promulgado leyes basadas en ella, en un total de 23 países que corresponden a: Australia (2008), Canadá (2005), Chile (2013), Colombia (2006), Eslovenia (2007), Estados Unidos de América (2005), Filipinas (2010), Grecia (2010), Japón (2000), Mauricio (2009), México (2000), Montenegro (2002), Nueva Zelandia (2006), Polonia (2003), Gran Bretaña (2006), Islas Vírgenes Británicas (2003), República de Corea (2006), Rumania (2002), Serbia (2004), Seychelles (2013), Sudáfrica (2000), Uganda (2011), Vanuatu (2013).

14 CNUDMI. Ley Modelo de la CNUDMI... y Guía para su incorporación, op.cit., p.29 
Revista Tribuna Internacional

Volumen $4 \cdot \mathrm{N}^{\circ} 8 \cdot 2015 \cdot$ pp. 165-183

ISSN 0719-482X (versión en línea)

\subsection{Recepción de la Ley Modelo en la nueva Ley de Insolvencia y Reemprendimiento}

De la revisión comparada entre el texto de la Ley Modelo y el texto aprobado en el Capítulo VIII de la NLI, intitulado "De la insolvencia transfronteriza", se puede concluir que se intentó respetar al máximo la estructura, el articulado y los términos utilizados en la Ley Modelo, procurando evitar cambios al articulado de la ley.

Esta intención se ve reflejada en las declaraciones que el asesor legislativo de la Superintendencia de Quiebras, Nicolás Velasco, hizo en el seno de la discusión legislativa: "Dado su origen internacional, es importante mantener la uniformidad de las denominaciones que se emplean, con el propósito de facilitar su aplicación entre las distintas legislaciones que las han adoptado",

Las palabras de Velasco van en línea con la recomendación que la propia CNUDMI hace en su guía para la incorporación al derecho interno, en cuanto a que la flexibilidad que entrega una Ley Modelo -que como lo expresa su nombre, es un texto legislativo que se recomienda a los Estados para incorporarlo a su derecho interno y no impone un texto rígido como en el caso de otros instrumentos internacionales- tiene que ir acompañada de un bajo número de cambios para preservar la armonización y seguridad jurídica que se quiere garantizar a los acreedores e inversionistas extranjeros.

De todas maneras, el legislador chileno sí introdujo algunos cambios al texto de la Ley Modelo, con el fin de adecuarlo a las particularidades del sistema jurídico nacional. Exceptuando los cambios de mera terminología, los cambios más relevantes que introdujo el legislador chileno son los siguientes:

1.- Artículo 301 b) de la NLI en relación con el artículo 2 b) de la Ley Modelo: El artículo 2 de la Ley Modelo establece ciertas definiciones relevantes, entre las que incluye la definición de procedimiento extranjero principal. Al definirlo, establece que será el procedimiento extranjero que se siga en el Estado donde el deudor tenga el centro de sus principales intereses. Por su parte, el artículo 301 b) modifica la definición anterior, disponiendo que se entenderá por procedimiento extranjero el que se tramite en el Estado "donde el deudor tenga su domicilio, entendiendo por tal el centro de sus principales intereses". Este cambio, le da un mayor énfasis a la relación entre el domicilio del deudor con el centro de principales intereses de éste, pero no cambia sustancialmente la definición y es redundante, teniendo en vista que ya en el artículo $315 \mathrm{~N}^{\circ} 3$ se establece que se presumirá que el domicilio del deudor es el centro de sus principales intereses.

2.- Se agregó en la NLI, las letras g) y h) al artículo 301, definiendo los conceptos de administradores concursales y tribunal competente, respectivamente.

15 Biblioteca del Congreso Nacional de Chile (BCN). Historia de la Ley No 20.720, p. 902 
3.- Artículo 305 de la NLI en relación con el artículo 6 de la Ley Modelo: Se modificó el artículo, cambiando el sentido del mismo. La redacción de la Ley Modelo reza: "Nada de lo dispuesto en la presente Ley impedirá que el tribunal se niegue a adoptar una medida en ella regulada, de ser esa medida manifiestamente contraria al orden público de este Estado". La excepción de orden público que puede esgrimir el tribunal está referida a una medida regulada en la Ley Modelo. Sin embargo, el legislador chileno, en la redacción de este artículo cambio por la siguiente redacción: "Lo dispuesto en el presente capitulo no impedirá que el tribunal competente y la Superintendencia se nieguen a adoptar una medida especifica dictada por un tribunal extranjero contraria al orden público de Chile". De esta manera, se volcó la excepción de orden público a una medida específica dictada por un tribunal extranjero y no a una medida regulada en la Ley Modelo. Se puede presumir que la intención del legislador fue ampliar el supuesto de la norma, para incluir cualquier medida, tanto que provengan de un tribunal extranjero como de la misma Ley Modelo. Suponemos que en esa misma dirección va la eliminación de la VOz "manifiestamente", que tiene la intención de subrayar una interpretación restrictiva de la excepción de orden público ${ }^{16}$.

4.- Artículo 308 de la NLI: Agrega como requisito para el acceso del representante extranjero a los tribunales chilenos, la comparecencia por medio de un abogado habilitado para el ejercicio de la profesión. La Ley Modelo no se pronuncia respecto a la necesidad de comparecer patrocinado por un abogado. La guía para la incorporación interna se limita a comentar que en este artículo se proclamar el principio de acceso directo, principio que exonera al representante extranjero de cumplir ciertos requisitos formales como determinados trámites consulares y licencias ${ }^{17}$.

5.- Artículo 313 de la NLI en relación con el artículo 14 de la Ley Modelo: Se eliminaron los numerales 1, 2 y 3 del artículo 14 de la Ley Modelo, que exigen que se notifique a los acreedores conocidos que no tengan una dirección en Chile. La NLI se remitió a establecer que las notificaciones se harán en la forma y plazos que fija esta misma ley.

6.- Artículo 314 de la NLI en relación al 15 de la Ley Modelo: Se agrega el requisito de legalización de todos los documentos públicos emitidos en el extranjero. El legislador chileno fue conservador en esta materia al exigir la legalización, en dirección opuesta a lo que recomienda la CNUDMI. En la Ley Modelo se presume que los documentos presentados en apoyo de la solicitud de reconocimiento no necesitan autenticación especial alguna, en particular, legalización ${ }^{18}$.

7.- $\quad$ Artículo $315 \mathrm{~N}^{\circ} 2$ de la NLI en relación con el artículo $16 \mathrm{~N}^{\circ} 2$ de la Ley Modelo: En concordancia con lo explicado en el número anterior, la presunción de autenticidad de

16 CNUDMI. Ley Modelo de la CNUDMI... y Guía para su incorporación, op.cit., p. 58, párrafo 104.

17 CNUDMI. Ley Modelo de la CNUDMI... y Guía para su incorporación, op.cit., p. 60, párrafo 108.

18 CNUDMI. Ley Modelo de la CNUDMI... y Guía para su incorporación, op.cit., p. 71. 
Revista Tribuna Internacional

Volumen $4 \cdot \mathrm{N}^{\text {o }} 8 \cdot 2015 \cdot$ pp. 165-183

ISSN 0719-482X (versión en línea)

documentos presentados en apoyo de la solicitud de reconocimiento del artículo $16 \mathrm{~N}^{\circ} 2$ de la Ley Modelo, se cambia por una referencia a que la autenticidad dependerá de la legalización exigida en el artículo anterior. Deja que desear la redacción de este numeral, ya que se habla de forma genérica de los documentos, sin distinguir entre documentos públicos y privados, lo que podría llevar a una interpretación más estricta que la propia legislación nacional, que en el artículo 345 del Código de Procedimiento Civil, exige legalización solo a los documentos públicos. De todas formas, la falta de distinción entre documentos públicos y privados se suple por la referencia que se hace al artículo 314 de la NLI en que se exige la legalización del 345 del Código de Procedimiento Civil referida a documentos públicos y además porque los documentos exigidos en el numeral 2 del precepto de la NLI para el reconocimiento de procedimiento extranjero, son documentos provenientes de tribunales o autoridades extranjeras ${ }^{19}$, por lo que cumplirían con la definición que nuestro derecho nacional hace de los documentos públicos como aquellos autorizados con las solemnidades legales por el competente funcionario. Sin embargo, en el caso del numeral 3 del artículo 314, que exige que se presente junto con la solicitud de reconocimiento una declaración en que se indiquen los datos de todos los procedimientos extranjero iniciados respecto del deudor de los que tenga conocimiento el representante extranjero, este puede ser perfectamente un documento confeccionado por el representante extranjero sin tener la calidad de documento público, sino de un documento simplemente privado, lo que llevaría a una interpretación del artículo 315 $\mathrm{N}^{\circ} 2$ de la NLI más estricta que la legislación nacional exigiendo legalización de un documento privado.

8.- Artículo $325 \mathrm{~N}^{\circ} 2$ de la NLI en relación al artículo $26 \mathrm{~N}^{\circ} 2$ Ley Modelo: Aquí se mantuvo el formato de la Ley Modelo, referido a la cooperación y comunicación entre administradores concursales y representantes extranjeros, pero se incurrió en un error al repetir el mismo texto del artículo 324 que se refiere a la cooperación y comunicación entre el tribunal chileno y el extranjero. En vez de decir "El tribunal competente" al comienzo del $\mathrm{N}^{\circ}$ 2, debería decir "Los administradores concursales". La misma Ley Modelo en ese punto dispone literalmente como debe completarse la disposición por el legislador interno: "[indíquese la denominación de la persona o del órgano encargado de administrar una reorganización o liquidación con arreglo a la ley del foro]”, referencia clara a los administradores concursales y no a los tribunales competentes, como quedó plasmado en la NLI. Además, el título del artículo 325 se refiere explícitamente a la cooperación y comunicación directa entre los administradores concursales y los

19 Artículo $214 \mathrm{~N}^{\circ} 2$ de la NLI, “Toda solicitud de reconocimiento deberá presentarse acompañada de:

a) Una copia autorizada de la resolución en la que se declare iniciado el procedimiento extranjero y se nombre el representante extranjero; $\mathrm{o}$

b) Un certificado expedido por el tribunal extranjero en el que se acredite la existencia del procedimiento extranjero y el nombramiento del representante extranjero; o

c) Cualquier otro documento emitido por una autoridad del Estado extranjero en cuyo territorio se haya abierto el referido procedimiento, y que permita al tribunal competente llegar a la plena convicción de su existencia y del nombramiento del representante extranjero". 
representantes extranjeros. Es una desprolijidad vergonzosa que pasó inadvertida en el proceso de creación de la ley. Una posible consecuencia de este error es que -en la medida que los administradores concursales estén regidos por el principio de legalidad en sus actuaciones $^{20}$ (cuestión a definir que queda fuera del alcance de este trabajo)- se dejaría sin mandato legal a los liquidadores y veedores para que se comuniquen directamente con el tribunal extranjero, quedando en la ley una confusa e indeterminada obligación de "cooperar en la medida de lo posible con los tribunales extranjeros o los representantes extranjeros" 21 .

9.- Artículo 329 b) de la NLI en relación con el artículo 30 b) de la Ley Modelo: La letra b) del artículo 30 de la Ley Modelo dispone que en caso de haber sido reconocido un procedimiento extranjero no principal, si posterior a ello se reconociera un procedimiento extranjero principal, se deberán reexaminar las medidas otorgadas al procedimiento no principal en caso ser incompatibles con el procedimiento extranjero principal. La lógica interna de esta norma es que da preferencia al procedimiento extranjero principal, si lo hubiera ${ }^{22}$. La prelación del procedimiento extranjero principal se refleja en el requisito de que toda medida en favor de un procedimiento extranjero no principal (esté ya otorgada o esté por otorgarse) ha de ser compatible con el procedimiento extranjero principal ${ }^{23}$. La recepción de esta norma en la NLI no sigue esta lógica en absoluto. Por el contrario, inexplicablemente en la historia de la ley consta que el Capítulo VIII fue sometido a solo una proposición de la Superintendente y como consigna el Segundo Informe de Comisiones Unidas: "las restantes normas de este capítulo tuvieron distintas enmiendas de tipo formal" 24 . Entre estas últimas figura una desafortunada enmienda que suprime la expresión "tras el reconocimiento" 25 del texto original $^{26}$, con lo que se pierde el sentido de la norma, al eliminar el elemento temporal que le entrega sentido a la disposición, ya que ésta busca regular la coordinación de un procedimiento extranjero principal cuando previamente había sido reconocido un procedimiento extranjero no principal, sentido que se pierde al eliminar la palabra "tras".

20 El artículo $2^{\circ}$ de la NLI, en la definición de liquidador $\left(\mathrm{N}^{\circ} 19\right)$ y de veedor $\left(\mathrm{N}^{\circ} 40\right)$, los sujeta a la fiscalización de la Superintendencia de Insolvencia y Reemprendimiento.

21 Artículo $325 \mathrm{~N}^{\circ} 1$ de la NLI.

22 CNUDMI. Ley Modelo de la CNUDMI... y Guía para su incorporación, op.cit., p. 113 párrafo 234.

23 CNUDMI. La Ley Modelo de la CNUDMI sobre la insolvencia transfronteriza: La perspectiva judicial. Viena, 2012, pp. 85-86, párrafo 216. [en línea] <https://www.uncitral.org/pdf/spanish/texts/insolven/Judicial_Perspective_Ebook_spanish.pdf> [consulta: 20 de diciembre del 2015].

24 BCN, Historia de la ley, op.cit., p. 903.

25 BCN, Historia de la ley, op.cit., p. 1134

26 Para una mejor comprensión, el texto original del artículo 30 b) de la Ley Modelo señala: "Cuando un procedimiento extranjero principal sea reconocido tras el reconocimiento o una vez presentada la solicitud de reconocimiento de un procedimiento extranjero no principal, toda medida que estuviera en vigor con arreglo a los artículos 19 o 21 deberá ser reexaminada por el tribunal y modificada o dejada sin efecto caso de ser incompatible con el procedimiento extranjero principal" (subrayado agregado). 
También se desdibuja la preeminencia que la Ley Modelo le quiere dar a los procedimientos principales por sobre los no principales, ya que no queda clara esa intención con la redacción chilena de la norma. El resultado es que según la interpretación del sentido literal de la disposición, ésta regula dos supuestos ${ }^{27}$ :

a) Que se reconozca un procedimiento extranjero principal estando en vigor alguna de las medidas del artículo 318 o 320. En ese supuesto el tribunal tiene el deber de reexaminar las medidas otorgadas en caso de ser incompatibles con un procedimiento extranjero principal. Las medidas del artículo 318 y 320 pueden otorgarse a procedimientos principales y no principales, sin embargo queda claro que este artículo no es aplicable al supuesto en que las medidas del 318 o 320 se hayan otorgado a un procedimiento extranjero principal o a la solicitud de su reconocimiento, ya que es imposible que existan 2 procedimientos principales. Queda entonces que en este primer supuesto, la letra b) del artículo 329 se aplica solo para reexaminar las medidas judiciales otorgadas a un procedimiento no principal, en caso que se haya reconocido previamente un procedimiento extranjero principal.

b) Que se presente una solicitud de reconocimiento de un procedimiento extranjero no principal, estando en vigor alguna de las medidas del artículo 318 o 320 . Aquí nuevamente tenemos que analizar si las medidas del artículo 318 o 320 fueron otorgados a un procedimiento principal o no principal. Si fueron otorgadas a un procedimiento extranjero no principal, estaríamos frente a la coordinación de dos procedimientos no principales, y quedaría sin sentido el final del artículo que habla de reexaminar las medidas en caso de ser incompatibles con un procedimiento principal.

Si las medidas de los artículos 318 o 320 fueron otorgadas a un procedimiento principal, la norma estaría expresando que se tiene que reexaminar las medidas otorgadas a un procedimiento principal si se presenta la solicitud de un procedimiento no principal, lo que anularía la preeminencia de los procedimientos principales por sobre los no principales. Es en este segundo supuesto en que queda de manifiesto el error que se cometió al eliminar las palabras "tras el reconocimiento", ya que el segundo supuesto que analizamos, que surge de la truncada expresión "o una vez presentada la solicitud de reconocimiento de un procedimiento extranjero no principal”, queda huérfana de significado. En consecuencia, la redacción actual del artículo 329 b) de la NLI, carece de un

27 Para una mejor comprensión, el texto aprobado en el artículo 329 b) de la NLI señala: "Cuando un procedimiento extranjero principal sea reconocido o una vez presentada la solicitud de reconocimiento de un procedimiento extranjero no principal, toda medida que estuviere en vigor con arreglo a los artículos 318 o 320 deberá ser reexaminada por el tribunal competente y modificada o dejada sin efecto en caso de ser incompatible con el procedimiento extranjero principal". 
sentido claro, por lo que en nuestra opinión se deberá recurrir a una interpretación extensiva de la norma, incluyendo en esta el supuesto original de la Ley Modelo, según se ha señalado, de tal modo que esta disposición tenga un sentido claro y tenga funcionalidad en la coordinación de los procedimientos extranjeros.

10.- Artículo 329 c) de la NLI en relación con el artículo 30 c) de la Ley Modelo: La Ley Modelo regula el caso en que se haya reconocido un procedimiento extranjero no principal y posteriormente se reconozca otro procedimiento no principal distinto al primero, coordinando las medidas judiciales otorgadas a cada procedimiento, de tal modo que se facilite la existencia de ambos procedimientos. Lamentablemente, al igual que lo ocurrido en el número anterior, se reemplazó la expresión "Cuando una vez reconocido un procedimiento extranjero no principal, se otorgue reconocimiento a otro procedimiento extranjero no principal" 28 por "Cuando un procedimiento extranjero no principal esté reconocido o se le otorgue reconocimiento" 29.30 De esta forma se cambió el sentido original del texto de la Ley Modelo, para remplazarlo por un supuesto más general, cual es que cada vez que se reconozca un procedimiento no principal, el tribunal tendrá que conceder, modificar o dejar sin efecto toda medida que proceda a fin de facilitar la coordinación de los procedimientos. La actual redacción del artículo, al no establecer un supuesto claro como el de la Ley Modelo, pareciera regir también en caso de existir un procedimiento principal y uno no principal, generando confusión con respecto a la letra a) del mismo artículo 329 de la NLI. Hay que aclarar el ámbito de aplicación de cada disposición: La letra a) rige para las medidas judiciales que se le otorgan a los procedimientos no principales cuando ya existía un procedimiento principal; en cambio la letra c), al no identificar qué procedimientos se están coordinando y simplemente hablar de "facilitar la coordinación de los procedimientos", perdería vigencia ante la formulación más específica de la letra a), siendo solo aplicable a la coordinación entre dos procedimientos no principales, mismo supuesto establecido en la Ley Modelo, pero con una redacción más confusa.

11.- Supresión del artículo 31 de la Ley Modelo: En la NLI se suprime el artículo 31 de la Ley Modelo, que establece una presunción de insolvencia del deudor respecto del cual se reconozca un procedimiento extranjero principal, constituyendo ese hecho prueba válida para efectos de la apertura de un procedimiento de insolvencia en el país en que se reconoció el procedimiento extranjero principal. Este es un efecto más que la ley le otorga al reconocimiento de un procedimiento extranjero principal, que al ser suprimido

28 El artículo 30 c) de la Ley Modelo señala: “Cuando, una vez reconocido un procedimiento extranjero no principal, se otorgue reconocimiento a otro procedimiento extranjero no principal, el tribunal deberá conceder, modificar o dejar sin efecto toda medida que proceda para facilitar la coordinación de los procedimientos".

29 BCN, Historia de la ley, op.cit., p. 1135.

30 El artículo 329 c) de la NLI señala: “c) Cuando un procedimiento extranjero no principal esté reconocido o se le otorgue reconocimiento, el tribunal competente deberá conceder, modificar o dejar sin efecto toda medida que proceda para facilitar la coordinación de los procedimientos". 
en la ley chilena, implícitamente le resta importancia a la distinción entre procedimiento extranjero principal y no principal, al quitarle un efecto al reconocimiento de un procedimiento extranjero principal.

\section{Centro de principales intereses del deudor}

Habiendo sentado las bases conceptuales de la insolvencia transfronteriza y su introducción en Chile, nos concentraremos ahora en el concepto de centro de principales intereses del deudor, para lo cual es necesario comenzar aclarando el marco en el cual se desenvuelve este concepto tanto en la Ley Modelo como en la NLI. Iremos por tanto de lo más general a lo más específico.

\subsection{Procedimiento extranjero}

Toda la regulación de la insolvencia transfronteriza en la NLI, gira en torno al concepto de procedimiento extranjero. Como afirma Sandoval: "La piedra angular sobre la que se sustenta el ámbito de aplicación de la Ley Modelo es la noción de procedimiento extranjero, porque gracias a ella se describen las situaciones a las cuales se aplican las reglas uniformes" ${ }^{\prime 1}$.

El procedimiento extranjero es definido en el artículo 301 de la NLI como "el procedimiento colectivo, ya sea judicial o administrativo, incluido el de índole provisional, que se tramite en un Estado extranjero con arreglo a una ley relativa a la insolvencia y en virtud del cual los bienes y negocios del deudor queden sujetos al control o a la supervisión del tribunal o representante extranjero, a los efectos de su reorganización o liquidación”. De la definición se pueden derivar varios elementos ${ }^{32}$ :

1.- Procedimiento colectivo: La Ley Modelo tiene por objeto servir de instrumento para llegar a una solución coordinada y global para todas las partes interesadas en el procedimiento colectivo. Al evaluar si un determinado procedimiento es colectivo a efectos de la Ley Modelo, una de las consideraciones fundamentales es determinar si en el procedimiento se tienen en cuenta prácticamente todos los bienes y las deudas del deudor, sin perjuicio de las prioridades y excepciones legislativas del país, ni de la exclusión, en su ordenamiento jurídico, de determinados derechos de los acreedores garantizados. De la revisión de jurisprudencia que ha deliberado respecto a la naturaleza

31 SANDOVAL, "La ley modelo de la CNUDMI...., op.cit., p. 36

32 CNUDMI. Ley Modelo de la CNUDMI... y Guia para su incorporación, op.cit., pp.44-47. 
colectiva de un procedimiento, se ha llegado al consenso que el carácter colectivo viene dado principalmente, por ser un procedimiento que incluya a todos los acreedores o a la mayor parte de ellos ${ }^{33}$.

2.- Con arreglo a una ley relativa a la insolvencia: Se busca que el procedimiento se base en una ley que regule la insolvencia o que por lo menos regule o aborde cuestiones relacionadas con la insolvencia.

3.- Control o supervisión de un tribunal extranjero: Cumplen este requisito aun los procedimientos en que el deudor conserva cierto control sobre sus bienes.

4.- A los efectos de su reorganización o liquidación: Quedarían fuera del ámbito de aplicación de la ley los procedimientos extranjeros que buscan impedir la dispersión y el desperdicio de bienes y no liquidar o reorganizar la masa de la insolvencia, así como también, meros acuerdos financieros entre un acreedor y alguno de sus deudores.

\subsubsection{Procedimientos extranjeros principales y no principales.}

Habiendo aclarado el concepto de procedimiento extranjero, corresponde, para efectos de analizar el concepto de centro de principales intereses del deudor, hacerse cargo, en primer lugar, de la clasificación que hace la Ley Modelo -así como también en su incorporación a la NLI- entre procedimientos extranjeros principales y no principales.

Un procedimiento extranjero principal es aquel procedimiento colectivo que se tramita en un Estado extranjero con arreglo a una ley relativa a la insolvencia para los efectos de su reorganización o liquidación, siendo ese Estado extranjero el lugar donde el deudor tiene su centro de principales intereses, que normalmente corresponderá al lugar de su domicilio social, según la definición del artículo 315 de la NLI. A su vez, un procedimiento extranjero no principal es aquel procedimiento colectivo que se tramita en un Estado extranjero con arreglo a una ley de insolvencia para los efectos de su reorganización o liquidación, siendo ese Estado extranjero el lugar donde el deudor tiene un establecimiento, que se define como todo lugar de operaciones en que el deudor ejerza de forma no transitoria una actividad económica con medios humanos y bienes o servicios, sin ser este el centro de sus principales intereses.

\subsubsection{Origen y propósito de la distinción}

Como ya hemos dicho, la normativa sobre insolvencia transfronteriza funciona en base a la existencia tanto de procedimientos principales como de procedimientos no principales. Cabe preguntarse por qué era necesario que existieran estas dos categorías. Quizás habría sido más eficiente que existiera un procedimiento principal, que tuviera la posibilidad de ser reconocido en diversas jurisdicciones para lograr la unidad en la liquidación o reorganización de la empresa insolvente. Esta cuestión fue debatida al interior del grupo de trabajo que elaboró la Ley

33 CNUDMI. La Ley Modelo de la CNUDMI... La perspectiva judicial, op.cit., p. 30, párrafos 75-78. 
Revista Tribuna Internacional

Volumen $4 \cdot \mathrm{N}^{\circ} 8 \cdot 2015 \cdot$ pp. 165-183

ISSN 0719-482X (versión en línea)

Modelo, llegando a la conclusión de que se debía reconocer el fenómeno de una posible pluralidad de procesos de insolvencia, ya que no era apropiado para la comisión estar restringiendo la apertura valida de procedimiento de insolvencia en otros países, la Ley Modelo debiera maximizar la cooperación y coordinación entre procesos celebrados en más de una jurisdicción, lo que aumentaría su aceptabilidad por diversos Estados ${ }^{34}$.

Esta intención cooperadora entre procedimientos también se tuvo presente en el Reglamento del Consejo Europeo sobre la materia, que sirvió como texto base para la elaboración de la Ley Modelo. Allí se señaló que "con objeto de proteger la diversidad de intereses, el presente reglamento permite que se incoen procedimientos secundarios paralelamente al procedimiento principal",35.

\subsubsection{Importancia de la distinción}

El concepto de centro de principales intereses del deudor se hace relevante para determinar si un procedimiento es reconocido como procedimiento principal o no principal. Que un procedimiento se reconozca como principal o no principal genera a su vez una serie de diferencias que se plasman en la ley, dándole un trato más favorable y preferente al procedimiento principal. Estos privilegios se expresan en:

1.- $\quad$ Las medidas previas y urgentes reguladas en el artículo 318 de la NLI, que se pueden otorgar a cualquier procedimiento de reconocimiento desde la solicitud de reconocimiento, podrán ser denegadas cuando afecten al desarrollo de un procedimiento extranjero principal.

2.- $\quad$ El artículo 319 de la NLI entrega medidas exclusivas a los procedimientos extranjeros principales. Estas medidas tienen la característica de ser automáticas, esto es, no son discrecionales para el juez y entran en vigor automáticamente junto con el reconocimiento del procedimiento ${ }^{36}$. La Guía de incorporación de la Ley Modelo al derecho interno es enfática en subrayar la importancia que las medidas del artículo 319 sean automáticas para dar el margen adecuado para organizar y tramitar de forma ordenada y equitativa el procedimiento de insolvencia transfronteriza. Estos efectos regirían, en términos chilenos, por el solo ministerio de la ley, desde que se notifique por el estado diario la resolución que otorgue reconocimiento al procedimiento extranjero principal.

3.- $\quad$ El artículo $320 \mathrm{~N}^{\circ} 3$ de la NLI establece una limitación de las medidas otorgadas a los procedimientos no principales, en el sentido de que deben circunscribirse a los bienes e información requeridos para ese procedimiento no principal. Estas disposiciones sugieren que las medidas en favor de un procedimiento extranjero no principal no deben

34 CNUDMI. Informe del grupo de trabajo $V$ sobre el régimen de la insolvencia acerca de la labor de su $18^{\circ}$ periodo de sesiones. Documento A7CN.9/419 de 1 de diciembre de 1995, p. 15, párrafo 72.

35 Párrafo 12 del Reglamento del Consejo Europeo, citado en CNUDMI. Ley Modelo de la CNUDMI... y Guía para su incorporación, op.cit..p. 49, párrafo 83.

36 CNUDMI. Ley Modelo de la CNUDMI... y Guía para su incorporación, op.cit., p. 89, párrafo 176. 
dar al representante extranjero unas facultades innecesariamente amplias y que las medidas no deben interferir en la administración de otros procedimientos de insolvencia, y menos aún en la del procedimiento principal ${ }^{37}$.

4.- Respecto a los artículos $322 \mathrm{~N}^{\circ} 2$ y 328 b) iii de la NLI, considérese lo indicado en el número anterior.

5.- $\quad$ El artículo 329 a) de la NLI exige la compatibilidad de las medidas otorgadas en el procedimiento no principal en caso de que se reconozca un procedimiento principal. Respecto a las letras b) y c), ya nos referimos en la crítica que hicimos de esas disposiciones en las páginas precedentes.

\subsection{El centro de principales intereses del deudor}

Habiendo caracterizado y contextualizado tanto el procedimiento extranjero como la distinción entre procedimientos extranjeros principales y no principales, haremos un análisis del concepto de centro de principales intereses del deudor.

\subsubsection{Ausencia de definición}

El centro de principales intereses del deudor no tiene una definición en la NLI, y en la Ley Modelo, por su parte, se adoptó deliberadamente la decisión de no definirlo. La idea de no precisarlo fue tomada del Convenio relativo a los Procedimientos de Insolvencia de la Unión Europea (el Convenio Europeo), por motivos de coherencia entre ambas fuentes legales ${ }^{38}$.

De todas formas, hay ciertos antecedentes importantes que nos permiten formarnos una idea preliminar sobre el contenido del concepto de centro de principales intereses del deudor.

\subsubsection{Aproximaciones al contenido del concepto de centro de principales intereses del deudor}

En primer lugar, tenemos la presunción establecida en el artículo $315 \mathrm{~N}^{\circ} 3$ de la NLI (artículo $16 \mathrm{~N}^{\circ} 3$ de la Ley Modelo). El citado artículo establece que salvo prueba en contrario, se presumirá que el domicilio social del deudor es el centro de sus principales intereses ${ }^{39}$. La presunción tiene por objeto facilitar el reconocimiento del procedimiento de insolvencia extranjero.

La relación que se hace con el domicilio social del deudor nos da una primera idea sobre el contenido del concepto de centro de principales intereses del deudor. La pregunta que surge es qué se entiende por el domicilio social del deudor. La respuesta que se ha dado a esa pregunta es que

CNUDMI. La Ley Modelo de la CNUDMI... La perspectiva judicial, op.cit., p. 67, párrafo 174.

CNUDMI. La Ley Modelo de la CNUDMI... La perspectiva judicial, op.cit., p. 36, párrafo 94.

39 La presunción también se extiende a la residencia habitual para el caso de la persona natural, elemento que no será analizado en este trabajo, por el énfasis dado a la situación de los grupos de empresas. 
“en el caso de las empresas y las personas jurídicas (...) el centro de los principales intereses del deudor es el lugar de su domicilio social, que corresponde al lugar en que tiene registrada su oficina. Este lugar normalmente corresponde a la oficina principal del deudor” ${ }^{\prime 40}$.

En el Derecho chileno, también se admite como domicilio social de la persona jurídica el que aparece en los estatutos de la sociedad ${ }^{41}{ }^{42}$

De todas maneras, el juez que reciba una solicitud de reconocimiento deberá juzgar la determinación del domicilio social en función de lo señalado anteriormente respecto a la interpretación de la Ley Modelo y a las normas internas referidas al domicilio social del país de origen de la solicitud.

En segundo lugar, podemos citar lo establecido en los párrafos introductorios del Reglamento del Consejo Europeo sobre la materia ${ }^{43}$. En ellos se dice que "el centro principal de intereses debería corresponder al lugar donde el deudor lleva a cabo de manera habitual la administración de sus intereses y que, por consiguiente, pueda ser averiguado por terceros" ${ }^{44}$.

El informe Virgos-Schmit, por su parte, explica la necesidad de que el lugar pueda ser conocido por terceros en base a que "la insolvencia es un riesgo previsible. Por consiguiente es importante que la jurisdicción se establezca a escala internacional en un lugar conocido por los posibles acreedores del deudor. De ese modo, podrán calcularse los riesgos jurídicos que se asumirían en caso de insolvencia" 45 .

De un modo más general, se ha dicho que los atributos esenciales del centro de los principales intereses del deudor se corresponden con los atributos que permitirían a quienes hagan negocios con este (especialmente a los acreedores) determinar el lugar en que es probable que se abra un procedimiento de insolvencia relativo a él ${ }^{46}$.

Otra forma de establecer nociones básicas sobre el concepto es haciendo énfasis en las expresiones que lo configuran. El propósito de utilizar el término intereses es abarcar no solo las

40 Virgos, Manuel y SCHMit, Etienne. Report on the convention of Insolvency procedings. Bruselas, 1996, p. 52, párrafo 75. [en línea] <http://aei.pitt.edu/952/> [consulta: 20 de diciembre del 2015]. Este informe, conocido como el Informe Virgos-Schmitt, se elaboró en relación al Convenio Europeo sobre Insolvencia, y aunque este no entró en definitiva en vigor, se acepta como ayuda para la interpretación de la expresión "centro de principales intereses" que se utiliza en el Reglamento de la Unión Europea y en la Ley Modelo.

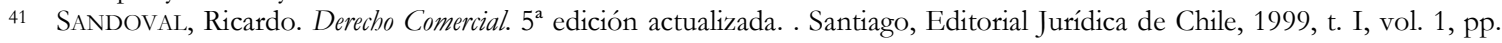
299-300.

42 Para un análisis más detallado del domicilio social de las personas jurídicas, vid. URRA, Fernando. El elemento espacial en el hecho imponible renta. Memoria para Optar al Grado de Licenciado en Ciencias Jurídicas y Sociales. Santiago, Universidad de Chile., 2010, pp. 48-56.

43 El Reglamento (CE) No 1346/2000 del Consejo, de 29 de mayo de 2000, sobre procedimientos de insolvencia, es la normativa que los países miembros de la Unión Europea se dieron para regular las situaciones de insolvencia transfronteriza. Utiliza, aun cuando tiene consecuencias distintas, el concepto de centro de principales intereses del deudor, por lo que se hace relevante para este trabajo.

44 Unión Europea. Reglamento (CE) No 1346/2000 del Consejo, de 29 de mayo de 2000, sobre procedimientos de insolvencia.

45 ViRgOS y SCHMiT, Report on the convention..., op.cit., p. 52, párrafo 75.

46 CNUDMI. Ley Modelo de la CNUDMI... y Guía para su incorporación, op.cit., p. 76, párrafo 144. 
actividades comerciales, industriales o profesionales, sino también las actividades económicas en general, de forma que se incluyan las actividades de las personas físicas (por ejemplo, los consumidores). El término principales establece el criterio que ha de utilizarse para dirimir los casos en que los intereses representen actividades diversas gestionadas desde distintos centros $^{47}$. Esta explicación de la palabra principales es relevante para los grupos de empresas o holdings, que normalmente diversifican sus negocios, invirtiendo en distintos rubros, por lo que será necesario hacer un análisis sobre cuál es el negocio principal del grupo de empresa, y cuáles son secundarios, basado en criterios como el monto de inversión, cuán expandido está ese rubro en los países en los que el grupo de empresas tiene presencia, el plan de negocios a largo plazo del holding y otros.

En resumen, podríamos delinear el concepto de centro de principales intereses del deudor como aquel que corresponde al lugar en que el deudor tiene registrada su oficina, que corresponde normalmente a la oficina principal del deudor y que ese lugar debe ser fácilmente reconocible por terceros, específicamente los acreedores del deudor.

Esta definición básica debiera ser suficiente para que, en la mayoría de los casos, el juez que recibe una solicitud de reconocimiento pueda aplicar la presunción del artículo $16 \mathrm{~N}^{\circ} 3$ de la Ley Modelo (artículo $315 \mathrm{~N}^{\circ} 3$ de la NLI) y determinar el centro de principales intereses del deudor, resolviendo que se reconozca ese procedimiento como principal en el país de su jurisdicción. Sin embargo, en algunos casos de mayor complejidad este se vuelve de difícil determinación para el juez, siendo insuficiente la aplicación de la presunción, por lo que tendrán que utilizarse otros elementos de análisis.

Los elementos que se han citado como complementarios a la presunción y a los dos requisitos básicos de que i) sea el lugar donde se lleva a cabo la administración central del deudor y que ii) este sea reconocible por terceros, son los siguientes, sin tener el orden alguna influencia en su importancia:

1) El lugar en que se encuentran los archivos y los libros de contabilidad del deudor;

2) El lugar en el que se organizaba o autorizaba la financiación o se administraba el sistema de gestión del efectivo;

3) El lugar en que se hallan los bienes u operaciones principales del deudor;

4) El lugar en que se encuentra el banco principal del deudor;

5) El lugar en el que estaban sus empleados;

6) El lugar en el que se determinaba la política comercial;

47 VIRGOS y SCHMIT, Report on the convention..., op.cit., p. 52, párrafo 75. 
7) La jurisdicción de la legislación de control o de la legislación por la que se regían los principales contratos de la empresa;

8) El lugar desde el que se gestionaba la política de compras y ventas, el personal, las cuentas por pagar y los sistemas informáticos;

9) El lugar en el que se organizaban los contratos (de suministro);

10) El lugar desde el que se dirige la reorganización de la empresa del deudor;

11) La jurisdicción cuya legislación se aplicaba a la mayoría de los litigios;

12) El lugar en que el deudor era objeto de supervisión o reglamentación, y el lugar por cuya legislación se regía la preparación y auditoría de las cuentas y en el que éstas se preparaban y auditaban ${ }^{48}$.

\section{Conclusiones}

En términos generales, la introducción en Chile de normas que regulen la insolvencia transfronteriza, es claramente un avance hacia un sistema de insolvencia más inclusivo y de mayor atractivo internacional, que viene a inaugurar un verdadero sistema de insolvencia transfronteriza en el país, en vista de las escasas y asistemáticas normas que existían antes de la nueva ley. Es de esperar que su implementación se traduzca en una mejora del lugar que Chile ocupa en el ranking Doing business del Banco Mundial y en otras mediciones similares.

En cuanto a la recepción de la Ley Modelo en Chile, se evidencian varias deficiencias en cuanto a la técnica legislativa que se utilizó al modificar los artículos para incorporarlos a la NLI.

Con respecto a la determinación del centro de principales intereses del deudor, queda claro que este se asimila con el domicilio social del deudor, entendido como el que tiene registrado en sus estatutos sociales. Sin embargo, esa referencia no es por si sola suficiente para establecer el centro de principales intereses, sino que será necesario que el lugar del domicilio social del deudor sea además el lugar donde se encuentran sus oficinas principales, en donde lleva a cabo la administración principal de sus negocios y que además, esa locación sea previsiblemente conocida por sus acreedores.

48 CNUDMI. Ley Modelo de la CNUDMI... y Guía para su incorporación, op.cit., p. 77, párrafo 147. 